\title{
Artículo
}

Sala de Lectura

\section{Estilo comunicativo y estilo de vida del adolescente español}

\author{
Manuel Martí Sánchez
}

Universidad de Alcalá

RESUMEN: Con la intención de servir de alguna utilidad al profesor de Secundaria, se ha examinado la manera de hablar de los adolescentes españoles actuales como extensión de una manera de pensar y vivir. Ordenados jerárquicamente los diversos y heterogéneos rasgos de la variedad adolescente, postulamos un estilo comunicativo adolescente. Destacamos en él los enunciados metarrepresentativos, reflejo de una poderosa metacognición, el dominio de las funciones expresiva y apelativa, así como el papel de las redes sociales en la difusión y creación de esta variedad. La relación entre estilo comunicativo adolescente y su estilo de vida nos ha llevado a su lenguaje formulaico y a la búsqueda de la identidad, que caracteriza esta etapa de la vida humana. A la vista de este panorama, las últimas preguntas se dirigen a lo que puede ofrecer al profesor de Lengua y Literatura todo este estudio y lo que él puede hacer.

PALABRAS CLAVE: Adolescentes, estilo comunicativo, estilo de vida, redes sociales, individualización, proximidad comunicativa, lenguaje formulaico.

\section{Communicative style and lifestyle of the Spanish adolescent}

ABSTRACT: With the intention of serving the high school teacher of some use, the way Spanish adolescents speak nowadays has been examined as an extension of a way of thinking and living. Having ordered hierarchically the diverse and heterogeneous traits of the adolescent variety, we postulate an adolescent communicative style. We highlight in it metarepresentative utterances, as a reflection of a powerful metacognition, the power of expressive and appealing functions, as well as the role of social networks in the dissemination and creation of this variety. The relationship between the adolescents' communicative style and their lifestyle has led us to their formulaic language and search for identity, which characterizes this stage of human life. In view of such panorama, the last questions are aimed at what this study can offer to the Language and Literature teacher as well as what the teacher can do.

KEYWORDS: Adolescents, communicative style, lifestyle, social networks, individualization, communicative immediacy, formulaic language. 
Del caos interior, de los instintos que se despiertan, de una vaga y tremenda inquietud de raíz casi biológica, que impregna la atmósfera de la "edad prohibida". Es el salto de lo informe a lo

formado, de la posibilidad a la realidad, del tránsito de una vida, poco menos que animal, entregada a los estímulos circundantes, a la vida humana. La "prohibición" es la distancia que existe, en la intimidad, entre las corrientes submarinas, que pugnan por aflorar, y ese deseo de ser uno mismo, que es el misterio que consagra la adolescencia.

(J.J. López Ibor).

No es en la universidad donde se libran las más decisivas batallas contra la barbarie y el vacío, sino en la enseñanza secundaria, y en barriadas deprimidas como la de Seine-Saint-Denis.

(G. Steiner, en Steiner y Ladjali 2005 [2003]: 18).

Toda generación se diferencia en la manera de hablar de las precedentes, en un cambio que es también de valores y comportamientos, y motivo habitual de crítica y parodia. Esta ley general de la Humanidad se ha incrementado tras las revoluciones culturales de fines de los años 60, con la consecuencia de que no solo se ha abierto una gran brecha entre modernos y antiguos, sino que los adolescentes, estandarte de los primeros, han adquirido una fuerza en la sociedad hasta la fecha desconocida, de modo que muchas de sus peculiaridades, también las lingüísticas, se han trasladado a otras franjas de edad: la juventud y madurez, por un lado; la infancia, por otro. Así las cosas, las diferencias entre la lengua adolescente y juvenil se han diluido hasta hacer posible referirse a ambas no solo como un continuo, sino como una unidad. Este supuesto se adoptará en estas páginas.

Sobre este fondo, vamos a poner el foco en el estilo comunicativo adolescente desde la perspectiva de que este forma parte de un estilo de vida. Es difícil ir más allá de las generalizaciones superficiales y abusivas con los adolescentes y su lengua, aun así, esperamos ayudar de algún modo con estas páginas a los profesores de Secundaria y Bachillerato, no solo por el hecho obvio de que cuanto más conozca a sus alumnos, más eficiente podrá ser su enseñanza. Las cuestiones que irán abordándose serán las siguientes: a) estilo comunicativo del adolescente actual; b) relaciones con el estilo de vida adolescente; y c) trabajo posible del profesor de Lengua y Literatura en Secundaria y Bachillerato. 


\title{
1. Introduciéndose en la lengua adolescente
}

\subsection{Su lugar en la variación lingüística}

Ninguna nueva generación, en cuanto alcanza una cierta autonomía, ha dejado de diferenciarse en un grado mayor o menor de la manera de hablar, sobre todo, cuando es entre iguales, de la de los adultos, hasta que, adultos sus mismos miembros, su manera de hablar se acomoda al estándar, naturalmente, modificado. Al mismo tiempo, la manera de hablar de los adolescentes siempre ha sido criticada por los adultos. Como en "Varón" del poeta extremeñista (aunque nacido en Salamanca) J. M. ${ }^{a}$ Gabriel y Galán, donde un padre dice de su hijo:

\author{
Ya no dici padri, \\ ni madri, ni agüela. \\ 'Mi papá, mi mamá, mi abuelita...' \\ así chalrotea, \\ como si el mocoso juesi un señoruco \\ de los de nacencia.
}

(Extremeñas, 1902)

Los padres de ahora no se quejan de que sus hijos hablen muy fino, sino de lo contrario, pero siempre han solido estar disconformes con las maneras de hablar de sus hijos.

Entendidos como un grupo dentro de la sociedad, transversal de las distintas clases sociales (cf. Cianca y Gavilanes 2018: 148) y, en parte, de los diferentes geolectos, es lógico que la manera característica de hablar de los adolescentes se haya considerado un sociolecto (Molina 2010: 200), un dialecto social (Halliday 1998 [1978]: 50) o un argot (Casas 1993: 111). Sin embargo, la variedad adolescente está muy ligada a determinadas situaciones comunicativas, por lo que funciona también como un registro, de ahí que se torne oportuna la muy citada definición de A. Briz (2003: 142), más cuando no distinguimos aquí entre lenguaje adolescente y juvenil:

Por lenguaje de los jóvenes entendemos la interacción coloquial de o entre los jóvenes, una submodalidad, un subregistro marcado social y culturalmente, que presenta en correlación con dichas marcas y las propias de la situación una serie de características verbales y no verbales [...]. Es decir, eso que se ha llamado lenguaje juvenil se inscribe dentro de la tradición 
oral, del discurso conversacional [...], está marcado, así pues, por la inmediatez comunicativa y se refiere más en concreto a la modalidad coloquial (Briz 2003: 142).

Se deduce de esta definición que la variedad adolescente esté marcada culturalmente, lo que nos ayudará a establecer su relación con un estilo de vida; y nos interesa que sea una variedad de la inmediatez comunicativa, dado el contexto de situación en que se produce y las estrategias de verbalización utilizadas. Un vistazo al conocido esquema de Koch y Oesterreicher (2007 [1990]: 34) nos ayudará a ver con más claridad lo que está queriéndose decir:

Inmediatez

\begin{tabular}{|l|}
\hline a) comunicación privada \\
b) confianza \\
c) emocionalidad \\
d) anclaje en situación y acción \\
comunicativas \\
e) posible referencialización \\
\\
desde aquí y ahora del \\
hablante \\
f) proximidad física \\
g) fuerte cooperación \\
h) carácter dialógico \\
i) espontaneidad \\
j) libertad temática \\
k) etc. \\
\hline
\end{tabular}

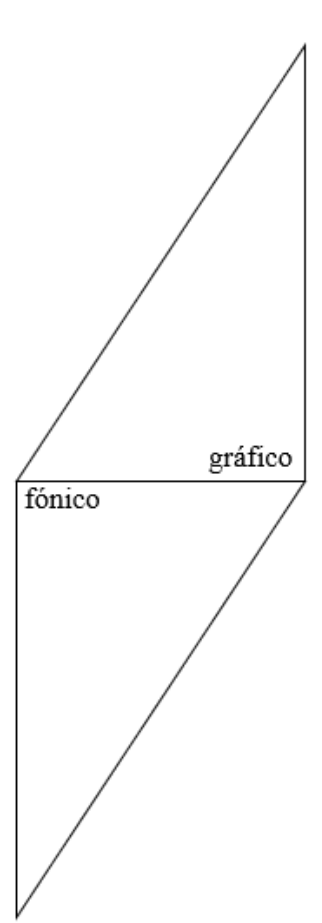

Distancia

a') comunicación pública

b') desconocimiento

c') ninguna emocionalidad

d') independencia de la situación acción comunicativas

e') imposible referencialización desde el aquí y ahora del hablante

f) distancia física

g') débil cooperación

h') carácter monológico

i') reflexión

j') fijación temática

$\mathrm{k}^{\prime}$ ) etc.

Estrategias de verbalización

contextualización lingüística

alta planificación

carácter definitivo

sintaxis integrativa

etc.

Esquema 1. Oposición inmediatez/distancia comunicativas.

Si se repasan los rasgos de la inmediatez comunicativa del esquema, la variedad adolescente, tal y como se verá un poco más abajo, se ajusta a las condiciones comunicativas y a las estrategias de verbalización de la inmediatez comunicativa. No obstante, se impone alguna matización. En lo que respecta a la libertad temática de la inmediatez comunicativa, la variedad adolescente, limitada a ciertas situaciones comunicativas, se centra en unos temas concretos de conversación y adolece de una notable monotonía expresiva. Por esta limitación, la variedad adolescente recuerda el código restringido de B. Bernstein (ver, más abajo, \$4). Además, la inmediatez comunicativa se caracteriza también por la espontaneidad y volvemos a ver que esta propiedad se da en la variedad adolescente hasta cierto punto solo, pues entre los adolescentes es fuerte la creatividad artificiosa y el uso consciente. Las matizaciones que 
acaban de hacerse refuerzan la transversalidad de la variedad adolescente y la idea, ligada a la doble consideración de dialecto social y registro, de que la variedad adolescente es, sobre todo, la manera de hablar de los adolescentes, en la medida en que estos constituyen una unidad, si bien de perfiles difusos, en unos contextos de situación bastante definidos.

\subsection{Adolescentización de la población y de su lengua}

Una de las transformaciones de estos tiempos de tanto cambio ha sido la prolongación de la adolescencia, la edad prohibida como reza el título de la novela de T. Luca de Tena de 19587, modificando su espacio clásico entre la niñez y la juventud. Ahora la adolescencia llega hasta los límites tradicionales de la edad adulta abarcando los primeros, al menos, años de juventud. Esto ha supuesto al mismo tiempo el alargamiento de la juventud con la consiguiente mengua de la madurez y de la vejez, esta cada vez más escondida. Igualmente, ha abierto cada vez más la zanja cultural entre todo este mundo joven o que quiere serlo y la gente mayor, cada vez más arrinconada. En fin, este proceso de adolescentización ha traído la aparición de la nueva categoría del preadolescente ${ }^{8}$, pronto truncada en prea; como adolescente, en ado. Los truncamientos solo ocurren con palabras que representan realidades habituales y socialmente relevantes.

La OMS se hace eco de este alargamiento de la adolescencia al definirla como "el periodo de crecimiento y desarrollo humano que se produce después de la niñez y antes de la edad adulta, entre los 10 y los 19 años". También, y más decididamente, recoge estos nuevos márgenes de la adolescencia R. Mendoza Berjano (2008:51), para el que "la adolescencia puede ser definida como la etapa de transición social que, en determinadas sociedades, se da entre la infancia y la adultez social". Son importantes las restricciones de adultez social y de en determinadas sociedades, porque en otras, en las que no hay familia o la incorporación al mundo del trabajo es muy rápida, solo hay pubertad. "Mi juventud... ¿fue juventud la mía?" se preguntaba en un conocido verso Rubén Darío, que han podido hacer suyo muchas personas de cualquier tiempo y sociedad.

Tal extensión de la adolescencia actual en nuestras sociedades se manifiesta en hechos tan diversos como la popularidad del síndrome de Peter Pan, la tardanza creciente en

\footnotetext{
${ }^{7}$ Es interesante ver la influencia en la construcción del estereotipo de la adolescencia ejercida por la literatura (Morán 2019), el cine (Rodríguez Merchán 2013) y ahora las series de televisión (Raya, Sánchez-Labella y Durán 2018). Del peso de los distintos géneros audiovisuales que circulan por Internet se hablará más adelante.

${ }^{8}$ Sobre la aparición de este neologismo, puede consultarse este blog: https://blogscvc.cervantes.es/martesneologico/preadolescente/.

${ }^{9}$ https://www.who.int/maternal_child_adolescent/topics/adolescence/dev/es/.
} 
independizarse, llamar a la gente fuera del círculo íntimo por su hipocorístico, la indefinición hasta casi la ancianidad de aspectos accidentales o esenciales de la identidad personal que antes solían estar muy claros al poco de cruzar la barrera de los veinte años; o, en fin, por terminar esta enunciación un poco frívolamente, que a adultos entrados en años se les vea comprando prendas para ellos en la planta de adolescentes de los grandes almacenes.

En medio de este cambio, la variedad adolescente se ha incorporado, como no podía ser de otro modo, a la lengua coloquial general (Molina 2010: 202), de tal manera que no es fácil aislar la variedad adolescente de la lengua coloquial, independientemente casi de la edad del hablante. Así las cosas, se impone matizar la arraigada idea de que la manera de hablar del adolescente se cura con el tiempo, en favor de las variedades más formales, cuando el individuo capta lo que es el mercado lingüístico, donde la lengua como capital cotiza.

Además, la adolescentización de la que está hablándose ha empujado a la lengua general hacia su coloquialización (Llopis y Pons Bordería 2020: 162). Así, no son extrañas expresiones, incluso escritas, independientemente de la edad de quien las profiere, tales como alucinar, tío, malqueda, rayarse, careto, hacer la cobra, caerle a alguien un marrón, valer una pasta, pavos (euros), kilos (millón de euros), comprar (dar por válido una idea, un plan...), postureo, meme, selfi, viejuno... o despedirse con un $c h a 0^{10}$. Quizá pueda dar una idea de lo que está queriéndose decir este mensaje en un foro español frecuentado por adultos, pero con un pensamiento, una manera de hablar y una temática adolescentes:

\footnotetext{
10 "Ud. está flipado" le espetó un miembro del Parlamento español a otro en una sesión solemne y un miembro del Gobierno acusó a la oposición de "estarse descojonando" ante una información. Es significativa la presencia en los discursos de los políticos pronunciados en instituciones tan altas como las Cortes no solo de estas expresiones, sino de otras tradicionalmente calificadas de groseras. Esta tendencia ha llegado también a los textos académicos. "Marchando una de ejercicios de reflexión sintáctica" es una entrada, que podemos considerar profesional, del blog de una joven y destacada lingüista (https://morfologiasinlimites.wordpress.com/2021/03/ 06/marchando-una-de-ejercicios-de-reflexion-sintactica/). En los agradecimientos de una reciente tesis doctoral se lee: "a XX, quien ha aguantado estoicamente turras míticas". Y “Traduttore traditore? ¡Anda ya!" es el título de un artículo de hace unos años, publicado en una revista de Pragmática. Destacan este tipo de títulos en los campos de la fraseología y de la enseñanza de lenguas. En esta libertad de titular hay un influjo del mundo anglosajón, en el que, antes que en el hispánico, aparecieron títulos chocantes e informales. Esta relajación de las exigencias del estilo académico, cuyo nacimiento lo situamos cuando las guerras lingüísticas habidas en el seno del generativismo a fines de los años sesenta y principios de los setenta del siglo pasado, no ha impedido la aparición entre los lingüistas profesionales de un gran interés por la corrección lingüística y la escritura académica.
} 
¿Es "TIRAR FICHAS" el peor truco para ligar?

Pues eso shurs ${ }^{11}$ yo no conozco a nadie o casi nadie que ligue con ese método osea es patético y de pagafanter, a una tía le gustas o no le gustas es así de simple y tirarle fichas o decirle frasecitas no va a cambiar su opinión de ti, ten eso claro tirafichas profesional y mis amigos son super patéticos en el tema de tirar fichas, y me dicen: que funciona, que es lo mejor y yo me río de ellos, he de admitir que yo también he utilizado eso varias veces pero ninguna ha sido efectiva, lo más efectivo ha sido siempre que un amigo/a nos presente y al rato charlar y tener una conversación profunda.

Tira Fichas, dejaos ese método absurdo y denigrante. Di no a esto o y como último TDS PTS. Un saludet shurs

https://www.forocoches.com/foro/showthread.php?t=4361833

En un mundo en el que se han relajado mucho esas normas de conducta tradicionales que claramente marcaban el paso de la adolescencia a la madurez, no extraña que muchos adultos sigan hablando y comportándose como adolescentes. Es el modo de hablar y de vivir más cómodo.

En una de sus colaboraciones periodísticas, F. Lázaro Carreter (1979) comentaba hace más de cuarenta años la novedad de que los jóvenes tuvieran una forma de hablar específica, que calificaba de "hecho bastante nuevo" y explicaba "por los principios educativos que han desplazado, declarándolos bárbaros, los métodos antiguos: aquellos que consideraban al niño como un adulto inmaduro, y la infancia y la adolescencia como simples estados de transición". A esta razón, tras la que se percibe un espíritu crítico, añadía premonitoriamente otra:

Los jóvenes, desde hace algún tiempo, constituyen un sector especial dentro de la sociedad, halagado, solicitado y a veces explotado por la industria, el comercio y la política. Porque, en gran mayoría, han asumido completamente en serio ese papel otorgado y son muchos los que se salen de su clase social para integrarse en el sector de edad, dotado como tal de ideología, costumbres y distintivos propios.

Concluimos esta toma de contacto con la variedad adolescente con una obviedad: la variedad adolescente es una realidad caótica en el sentido matemático del término. F. Lázaro Carreter lo reconocía con esta matización: "este tipo de jerga generacional, mejor dicho, de

\footnotetext{
${ }^{11}$ Shurs es abreviatura de surmanos ('hermanos'). Es una palabra ligada al habla de la etnia gitana y se utiliza como vocativo entre iguales (http://diccionariolibre.com/definicion/surmano/19235).
} 
jerga de grupo generacional" (Lázaro Carreter 1980 [1978]: 245). Valga como argumento de la fragmentación de la variedad adolescente que al autor de estas páginas, joven en la época sobre la que escribe F. Lázaro Carreter, algunos de sus ejemplos le eran entonces desconocidos: calandria (peseta), tejo o guil (5 pesetas, el popular duro), ligar bronce 'ponerse moreno', [tener unas] cachas molonas, vinate ('vino'), donde hay un evidente cruce entre vino y el caló mollate ('vino corriente')... (1979 y 1980 [1978]: 244 y 245).

La variación se da en cualquier variedad etaria. Desde luego, en la adolescente, en los que son tan significativas las tribus urbanas, uno de cuyos signos de identidad es una jerga (ver abajo \$3.2). Precisamente, en esta disgregación de la variedad adolescente radica uno de los problemas que vemos en su estudio: la concentración en lo pintoresco y la elevación de lo particular a lo general.

Esta heterogeneidad no será un obstáculo para nuestros objetivos, pues lo que en estas páginas interesan son las tendencias generales que, con mayor o menor fuerza, se dan en esta lengua y permiten postular un estilo comunicativo adolescente. Lógicamente, tampoco existe un adolescente tipo español. Sería imposible, dada su diversidad, cruzada por varias distinciones, entre las que no es menor la que se da entre chicos y chicas ${ }^{12}$. Sin embargo, sí existe un estereotipo de adolescente, en el sentido de H. Putnam, como la "idea convencional" que se asocia a la palabra (Amossy y Herschberg Pierrot 2020 [1997]: 95) y que hacemos corresponder con la imagen dominante en la sociedad, de adolescente. En este doble sentido genérico nos basaremos para hablar de estilo comunicativo adolescente y de su estilo de vida.

Desde estos supuestos y de la mano de los rasgos principales de la variedad de los adolescentes españoles actuales, tal y como se recogen en corpus, estudios destacados y en nuestras propias informaciones de primera mano, el objetivo de este artículo se dirige hacia la relación entre el estilo comunicativo y el estilo de vida adolescentes. Tenemos motivos para pensar que existe esta relación porque la manera de hablar es de por sí una forma de conducta, tras la que late un pensamiento, en el que es atractivo suponer que la lengua que se habla tiene un papel. "Una lengua es una filosofía del mundo; [...] una manera de partir y de valorar lo real del mundo", decía A. Alonso, desde el idealismo lingüístico (apud Battista 2013).

\footnotetext{
${ }^{12}$ Sobre sus diferencias de conducta comunicativa es útil el TFG de J. Mamajón (2014).
} 


\section{El estilo comunicativo adolescente}

\subsection{Superficie y fondo del estilo comunicativo adolescente}

La variedad adolescente es un conglomerado heterogéneo de usos conscientes e inconscientes, intencionales y convencionales. Los más llamativos son ciertos rasgos concretos que se sitúan en "los niveles más superficiales de la lengua —el léxico, la fraseología, el discurso-" (Moreno Fernández 1998: 44). Son rasgos que producen inicialmente extrañeza por su carácter frecuentemente cómico, deliberadamente artificioso, condenados muchos de ellos a una pronta desaparición, como modas y exageraciones que son. La inestabilidad y dispersión de estos rasgos concretos remite cuando se agrupan en torno a unas categorías como los truncamientos, metáforas, fórmulas... y, sobre todo, a unas tendencias generales, como su carácter restringido, la informalidad, la renovación constante, la permeabilidad ante las modas y la desinhibición, a las que se suman la expresividad que se abre a la multimodalidad o al plurilingüismo. Estas constantes, tras las que subyacen los impulsos intersubjetivos (expresivos y apelativos) de la variedad adolescente, matizan la vieja idea del carácter efímero de la variedad adolescente: es efímero lo aparente, pero no lo que hay detrás.

En estas constantes de la variedad adolescente, que sabemos extendidas a otros segmentos etarios de la población, nos basamos para hablar del estilo comunicativo adolescente. Entenderemos estilo como "la manera de escribir o de hablar peculiar" (DLE) de un individuo, de un grupo o, incluso, de un pueblo. Lo definen las elecciones que continuamente hacen los hablantes en función de sus propósitos, del destinatario, donde ocupa un papel importante el cálculo de sus "capacidades interpretativas" (Escandell 1994: 56), y del entorno (situación, región, contexto y universo de discurso) (Coseriu 1955-56) ${ }^{13}$.

Nos inspiramos al hablar aquí del estilo comunicativo adolescente en el estilo conversacional de hombres y mujeres de D. Tannen (2005 [1984]) y en A. Wierzbicka, quien utiliza estilo comunicativo, de habla o discursivo ${ }^{14}$ preferido por alguna determinada comunidad, para referirse a las diferencias dentro de la textura lingüística en cosas tales como: "la frecuencia de los imperativos y preguntas, las formas de dirigirse y vocativos, las formas especiales de autorreferencia, la aceptabilidad de la negación abierta, el uso de la imprecisión

\footnotetext{
${ }^{13}$ Tales variables se corresponden con los tres encabezados que describen un contexto de situación: campo, tenor (relación entre interlocutores) y modo (Halliday 1998 [1978]: 49).

${ }^{14}$ En cierta medida es posible hablar del "estilo de discurso" preferido de una cultura en su conjunto, al menos si nos limitamos a la esfera pública, es decir, a situaciones en las que los participantes no se conocen muy bien y están siendo observados por otros mientras hablan (Goddard y Wierzbizka1997: 237). Dentro de la comunicación empresarial, Norton ha distinguido varios estilos comunicativos (communicator style) (Norton y Pettegrew 1977).
} 
y la no especificidad, exclamaciones y partículas discursivas, y el uso del vocabulario socialmente marcado" (Goddard y Wierzbicka 1997: 237).

En el esquema 2 ordenamos los fenómenos que conforman el estilo comunicativo desde los más superficiales a los más profundos, de los más concretos a los más generales.

\begin{tabular}{|l|l|}
\hline Rasgos concretos & $\begin{array}{l}\text { Imitación de acentos, variedades, pronunciaciones } \\
\text { deliberadamente vulgares (ta por está, to por todos, } \\
\text { finales en ao...), } \\
\text { prefijos, vocabulario, lenguaje formulaico, sintaxis } \\
\text { simplificada y parcelada }\end{array}$ \\
\hline Categorías & Acortamientos, metáforas, partículas, vocativos \\
\hline Tendencias y principios & $\begin{array}{l}\text { Emociones, mínimo esfuerzo, desinhibición, } \\
\text { informalidad, anticortesía, metarrepresentatividad }\end{array}$ \\
\hline Funciones & $\begin{array}{l}\text { Interpersonalidad, agresividad, orientación textual, } \\
\text { complicidad }\end{array}$ \\
\hline Medios & Interacción oral, redes sociales \\
\hline
\end{tabular}

Proximidad comunicativa, código restringido

Esquema 2. Estilo comunicativo adolescente.

A continuación, pasamos a describir los fenómenos verbales más relevantes del estilo comunicativo adolescente. Los más interpretables en términos de conducta general los reservaremos para el apartado siguiente. Los demás solo se mencionan en este esquema.

\subsection{Vocabulario y fraseología}

En efecto, lo que suele percibirse de modo más inmediato en la lengua de los adolescentes está en el léxico (Capanaga y San Vicente 2005: 75-85, 86-89; Hernández y Vigara 2007: 144 y 158), morfemas léxicos ${ }^{15}$ y unidades fraseológicas incluidas. Este vocabulario está muy concentrado en ciertas áreas, de ahí el fenómeno de la sobrelexicalización consistente en esa acumulación de sinónimos y cuasinónimos en torno a determinadas áreas temáticas

\footnotetext{
${ }^{15}$ Un caso muy significativo es el del prefijo super, bien pujante hoy, al que ya le dedicó F. Lázaro Carreter (1999) uno de sus dardos. Cianca y Gavilanes (2018: 148) señalan la productividad de -aco/a (tontaco, fiestaca).
} 
(Halliday 1998 [1978]:215). Nos imaginamos de qué áreas podemos estar hablando: el sexo y las relaciones sentimentales, el ocio y las drogas, los estudios y el trabajo.

Como ya se ha apuntado, este léxico adolescente suele ser muy fugaz, de modo que está a la orden del día también la incesante relexicalización, que reemplaza palabras existentes por otras, por razones de expresividad, no de eficiencia, en una búsqueda continua de novedad (Halliday 1998 [1978]: 214-215; Rodríguez González 2006: 35-36). "Eso ya no se dice" es un lugar común entre adolescentes cuando se les pregunta por un determinado uso ${ }^{16}$.

Basta echar un rápido, y puede que melancólico, vistazo, para hallarse con palabras y expresiones propias de los adolescentes anteriores, que estuvieron muy de moda: desgraciado (usado como insulto), virguero, cachondo (en su acepción de 'burlón, divertido, bromista' DLE) y derivados como cachondo mental, hortera y horterada, macho como vocativo y su fórmula asociada (¡jo, macho!), reemplazado en los años ochenta del siglo pasado por tío, también con sus fórmulas (¿qué pasa, tío?, ¿de qué vas, tío?) (Llopis y Pons Bordería 2020: 156-157, 158-159) y ahora, entre muchos, por hermano (bro o manin), de inequívoco origen afroamericano... Entre la juventud de la Posguerra fueron muy populares maquear, la fórmula jes fenómeno! o la locución a lo loco ${ }^{17}$. Mucho después vinieron otras, pero ya en vías de extinción, como el loro ('aparato de audio') y jal loro!, colgarse y colgado (https://cvc.cervantes.es/lengua/palabra_por_ palabra/pie_pagina.asp?pxp=5), pasar y su derivado pasota, rollo, castigar y castigador, tarro ('cabeza'), carroza y tarra ('viejo'), la expresión ser la caña, flipar y flipado (https://cvc.cervantes.es /lengua/palabra_por_palabra/pie_pagina.asp?pxp=9), abrirse 'marcharse', rayarse (https://cvc .cervantes.es/lengua/palabra_por_palabra/pie_pagina.asp?pxp=14)., o, en fin, una fórmula como ¡Qué demasiado!, con sus variantes ¡qué demasiado para \{el/mi\} body!, ¡qué demasié!...

Abundan los préstamos, algunos internos, importados mayoritariamente de los ámbitos más relevantes para el adolescente (marginalidad y delincuencia, música, deportes, sexo, la escuela y las redes sociales, antes, el servicio militar). De la marginalidad provienen marrón (con sus expresiones caerle a alguien un marrón, comerse un marrón), truño ('excremento', pero, aplicado a menudo a un libro o película, 'indigesto, pesado y sin valor') ${ }^{18}$ y los ya antiguos

\footnotetext{
${ }^{16}$ Una joven licenciada en Filología Inglesa abría un hilo de Twitter preguntando: “¿Les niñes/adolescentes siguen diciendo "molar", "guay" y "flipar"?" (https://twitter.com/andreapeal/status/1339130415274143745).

${ }^{17}$ Toda nueva generación tiene su manera de hablar, también de los que hicieron la Guerra. Diccionario para un macuto de R. García Serrano (1964) es una auténtica mina de información al respecto y un refrendo de la tesis de que toda nueva generación, con conciencia de tal, necesita, crea su propio estilo.

${ }_{18}$ Sobre esta palabra es interesante el siguiente hilo en un foro del Instituto Cervantes: https://cvc.cervantes.es/foros/leer_asunto1.asp?vCodigo=44425.
} 
gusa ('hambre'), chorizo, sobar ('dormir'), lache ('vergüenza'), jambo ('payo, persona que no es gitana')... Estos últimos tomados del romaní.

Por muchas razones obvias, la lengua inglesa surte de muchas palabras a estas generaciones mucho más familiarizadas con el inglés que las anteriores. La relexificalización se manifiesta en el empleo de anglicismos, de las que son unas muestras, con su explicación, estas entradas tomadas de un Diccionario millennial [sic] presentado como trabajo de clase por unas alumnas (Carla Martín, Natalia Molina e Irene Muñoz) de $3 .^{\circ}$ del Grado de Lenguas Modernas y Traducción de la Universidad de Alcalá (curso 2018-2019). Todo él está plagado, no por casualidad, de anglicismos:

Lol: 'siglas que en inglés significan "laughing out loud". En un principio, reírse a carcajadas. Actualmente se usa de forma sarcástica'. Ejemplo:-¿Me ayudas? —Pero, ¿quién te crees que soy?, lol.

Crush: 'palabra inglesa que designa a una persona que te gusta, pero que en principio es inalcanzable'. Ejemplo: Brad Pittes mi crush.

Outfit: 'palabra inglesa que significa conjunto de ropa'. Ejemplo: - ¿Qué outfit te vas a poner esta noche?-Una camiseta negra y unos vaqueros.

Wtf: 'del inglés "what the fuck", utilizado en caso de sorpresa, normalmente cuando esta es mala.' Ejemplo: - Juan y Julia lo han dejado, ¿lo sabías? -Wtf, no tenía ni idea.

Mood: 'palabra inglesa que se dice cuando te sientes identificado con un estado de ánimo'. Ejemplo:- Estoy súper cansada de estudiar. - Mood.

Raxeto, raxeta: 'chico, chica, normalmente usado para los ligues'. Ejemplo: Esta tarde va a quedar con el raxeto.

Shippeo: 'pareja de personas que quieres que tengan una relación amorosa'. Del inglés relationship. Ejemplo: Estoy cansado del shippeo Aiteda (acrónimo de los dos emparejados Aitana y Cepeda). Shippeo tiene como cuasinónimo carpeteo, por la costumbre adolescente de pegar fotos de ídolos del cine, la televisión o la canción en su carpeta de clase.

De chill: la palabra inglesa chill que hemos españolizado añadiendo "de". Se utiliza para decir que quieres hacer un plan tranquilo. Ejemplo: Hey ¿quedamos esta tarde de chill?

Same: 'palabra inglesa que se utiliza para expresar que estás de acuerdo con algo'. Ejemplo:Estoy harta del trabajo de inglés. —Same.

Un anglicismo emergente actualmente entre los adolescentes españoles y de otros países hispanos (https:/www.diccionarioargentino.com/term/simp) es simp (inglés simp 
‘bobo, pánfilo’), surgido dentro de la misma atmósfera de tirar fichas (ver, arriba, \$1.2.). Quizá dentro de dos años de publicarse este trabajo, la locución será ya una reliquia.

El vocabulario adolescente se nutre también de creaciones propias o ajenas, en las que se aprovechan los mecanismos del idioma. Los truncamientos y los ajustes léxicos son muy productivos. Los truncamientos y otras formas de abreviación, en los que no puede descartarse la influencia del inglés a través de la cultura norteamericana, están a la orden del día: profe, cole, finde, malro, bienro, prota, peli, tranqui... Aquí podríamos incluir los hipocorísticos cuyo uso ha traspasado los límites de la intimidad familiar y que se aplican también a nombres de lugar. Guadalajara es Guada; San Fernando de Henares, Sanfer; S. Agustín de Guadalix, Sanagus; el distrito de Madrid, Vallecas, Vk... Este último ejemplo nos pone delante de la proliferación de abreviaturas en los mensajes de las redes sociales y de ese afán identitario del que hablaremos más abajo, manifestado en etiquetar o autoetiquetar cualquier grupo: boomer, milenial, antifa, neonazi, cani, hipster, gamer...

El cambio semántico, como cambio de referencia, ocupa un papel importante en la conformación de la variedad adolescente en cada momento. Petar era originariamente 'agradar', 'estallar, explotar', explicable por su etimología del cat. petar'peer, agradar, estallar', de pet 'pedo' (DLE). Ahora ha desarrollado sentidos como 'llenar, abarrotar', en petarlo 'triunfar', incluso, en ámbitos minoritarios ‘sodomizar' (Cianca y Gavilanes 2018: 161).

El origen del cambio está siempre en el individuo, en la estilística, para luego, si se dan las condiciones, convencionalizarse ${ }^{19}$. La Pragmática léxica estudia esta primera fase en términos de ajustes léxicos que experimentan las unidades por su inserción en los enunciados concretos. Esta modulación consistiría en enriquecimientos de la unidad (restricción de la referencia), en debilitamientos (extensión de la referencia) y en transferencias, representadas por metáforas y metonimias, cuya relación con el debilitamiento es objeto de discusión (Romero y Soria 2020: 130-132).

Desde nuestra perspectiva, lo que vemos en este paso de una expresión ordinaria a otra propia de una variedad es una especialización de la referencia (cf. Fábregas 2013: 91). Es lo que se da, vía metáforas, en la locución a machete ('con todas las consecuencias', 'a saco'), turra (de

\footnotetext{
${ }^{19}$ Un ejemplo de estas últimas lo proporciona un youtuber muy popular entre los jóvenes españoles de hoy, Andrés de la Hoz. Este ha extendido el siguiente uso entre sus miles de seguidores “¿Todo bien? ¿Todo correcto? Y yo que me alegro". Es opinión común entre los adolescentes y jóvenes a los que les hemos preguntado en esta investigación que muchas de sus fórmulas, que estudiaremos en \$3.1, proceden de usos de estos youtubers, influentes y memes.
} 
torrar 'tostar' y de ahí, 'dar la brasa, cansar con las palabras'), patata ('corazón') o empanado (casi siempre, pronunciado con la caída de la /d/ intervocálica, empanao 'atontado, despistado').

Dentro de este mismo proceso de cambio, un fenómeno interesante es la revitalización en este vocabulario de palabras como cuqui ('muy mono, bonito'), fardar ('presumir') y locuciones (dar el) sobo, dar la brasa, perder aceite (Cianca y Gavilanes 2018). La reaparición de estas viejas palabras puede venir acompañada de cambios en la construcción que la albergaba. Es lo sucedido con mogollón o con chungo.

Mogollón es una palabra documentada en el Corpus Diacrónico del Español (CORDE) ya a fines del siglo XV. Habitualmente formaba parte de la locución de mogollón ('de balde, gratuitamente' y posteriormente, 'mal hecho, descuidadamente, con apresuramiento'). Luego ha pasado a funcionar como un cuantificador ("Yo tengo mogollón de cosas en qué pensar" CORPES XXI J. P. Villalobos, No voy a pedirle a nadie que me crea, México, 2016).

Chungo es otro ejemplo interesante. "Aunque se sigue oyendo el adjetivo (ser una cosa, o una persona, chunga: 'ser mala'), cada vez se emplea menos. Sin embargo, ha dado lugar a un nuevo uso, resultante de la sustantivación en masculino de este término: un chungo es un súbito estado de malestar intenso, un jari. Le ha dado un chungo" (Cianca y Gavilanes 2018: 154).

\subsection{Metarrepresentación}

"Durante la adolescencia la gente suele desarrollar una conciencia muy intensa tanto de sus propios procesos psicológicos como de los de los demás (metaconocimiento)" (Flavell, apud Bañón 2004: 51). Esto es así, al verse que uno de los signos del estilo comunicativo son las construcciones metarrepresentacionales. Como señala una de sus mayores estudiosas en la pragmática española, "una metarrepresentación es la representación de una representación. En este proceso, un constituyente representa a otro constituyente de la misma clase, al que contiene" (Reyes 2018:255). Muchas de estas metarrepresentaciones adolescentes, enunciados que contienen otras palabras u otros pensamientos, son parodias, entendiendo estas como ese fenómeno metarrepresentativo en que "la actitud disociativa implícita que el hablante comunica no es (solamente) hacia el contenido metarrepresentado, sino que atañe a la forma o al estilo de un original, que también se metarrepresenta en el discurso del hablante" (Curcó 2020: 227).

La metarrepresentación puede ser de uno mismo, convertido en centro de sus propias palabras, previo el necesario distanciamiento: 
1. Estoy un poco rayado en plan pf (corpus de Diego Gibanel, estudiantes de $2 .^{\circ}$ del Grado de Estudios Hispánicos de la Universidad de Alcalá).

2. A ver $\mathrm{x}$ ser mujer no tienes $\mathrm{xq}$ decir eso yo si soy mujer en plan no sbs pero si lo fuese en un supuesto gran caso pos yo $\mathrm{k}$ se iria con mis amigas hablaria de perfumes y empezaria a tirar fichas a todo simp k exista en plan tiene k ser super divertido dar falsas ilusiones a tios (https://twitter.com/tubro1k/status/1325440560543526914).

En (1) y (2) la locución en plan, santo y seña de los adolescentes españoles actuales, introduce un discurso autorreferido ( $c f$. Méndez Orense 2016:138-140; Catalá y Perdomo 2017: $16)^{20}$. En (1), se representa su propio estado anímico mediante lo que se dice característicamente en esta situación. Su carácter elíptico, la ausencia de puntuación y los anacolutos dificultan el análisis de $(2)^{21}$, pero en plan introduce en las dos veces en que aparece los pensamientos que esa mujer construida por el autor del tuit quiere suscitar.

También es posible la heterorrepresentatividad como en

3. MABPE201: ay borracha. MABPE202: se le ve la cara de estoy deseando alcohol (corpus Cola).

En (3), MABPE2O2 le atribuye a uno de sus interlocutores el deseo de ingerir alcohol mediante lo que, en su interior, estaría diciendo. Aunque no hay pistas en la transcripción sobre la prosodia, esta sin duda funciona como signo del carácter metarrepresentacional del enunciado.

4. Que quites el puto coche.

(4) es un enunciado escuchado a un joven que le decía a un amigo que apartara su automóvil, que estaba obstaculizando el paso de otro. En el ejemplo se percibía la cita encubierta: “iquita el puto coche!”, fórmula habitual en las discusiones automovilísticas por esta razón.

Como veíamos en el Diccionario millennial de las tres alumnas de Lenguas Modernas y Traducción, el acrónimo lol va asociado a un empleo irónico, por tanto, metarrepresentacional. Lol no se usa en (5) para describir un estado anímico, sino para

\footnotetext{
${ }^{20}$ En plan está especializándose en una de las constantes en el uso coloquial de la lengua: la presencia de "relatos, historias frecuentemente dramatizadas" que, al mismo tiempo, "favorece[n] el empleo del estilo directo, siendo éste (sic) [a su vez] otro de los rasgos característicos del español coloquial" (Briz 2001: 41-42).

${ }^{21}$ Así transcribe el texto Mayte Molina (del Máster Universitario en Formación de Profesores de Español): "A ver, por ser mujer no tienes por qué decir eso. Yo, si soy mujer, en plan...no ¿̇abes? pero si lo fuese en un supuesto gran caso, pues yo que sé... iría con mis amigas, hablaría de perfumes y empezaría a tirar fichas a todo simp que exista, en plan... tiene que ser súper divertido dar falsas ilusiones a tíos".
} 
caracterizar otro mediante el distanciamiento consciente de lo que representa normalmente el acrónimo:

5. Lol: 'siglas que en inglés significan "laughing out loud". En un principio, reírse a carcajadas. Actualmente se usa de forma sarcástica'. Ejemplo: - ¿Me ayudas? - Pero, ¿quién te crees que soy?, lol (Diccionario millennial).

\subsection{Funciones}

La atención a los fines de las interacciones adolescentes es obligada, pues los propósitos comunicativos de estas son factor explicativo fundamental y enlace imprescindible para conectar estilo comunicativo y estilo de vida adolescentes. Ordenaremos estos propósitos siguiendo las tres funciones semánticas del signo lingüístico de Bühler: representación, expresión y apelación, correspondientes a los tres momentos de aparición del signo lingüístico: símbolo, síntoma y señal (Bühler 1979 [1934]: 48). Que todo signo lingüístico sea, al mismo tiempo, símbolo, síntoma y señal es una manera de reconocer un triple nivel funcional de los enunciados, algo distinto del más conocido de F. Daneš (1966).

De las tres funciones, la menos interesante resulta aquí la representativa, pues los enunciados adolescentes prototípicos son escasamente referenciales, sus miras se dirigen más bien hacia sus emociones y hacia la interacción con los suyos. En lo que respecta a la función expresiva, los enunciados adolescentes característicos están cargados emocionalmente. Lo señala I. Darrault-Harris (2007): "el habla adolescente, oral, escrita, puede aparecer como un acto saturado de afectos"22. Esta carga emocional se presenta algo especialmente, pues, como el mismo Darrault-Harris (2007) señala, el discurso adolescente está, por un lado, hipersexualizado; pero, por otro, es muy pobre en lo que se refiere a la expresión de los sentimientos y las emociones.

En la variedad adolescente destacan también las expresiones prohibidas (groserías, blasfemias e insultos), explicables inicialmente por los efectos emocionales que produce la transgresión que conlleva su uso (Valenzuela 2018). Después, se queda en cómoda unidad de apoyo, desprovista de carga emocional y en signo de pertenencia al grupo.

En efecto, el insulto está muy presente entre los adolescentes y no solo cuando se comunican entre sí. Están de triste actualidad las ofensas dirigidas a sus padres. Los insultos más interesantes son los que se utilizan para etiquetar al destinatario de la ofensa en alguna categoría nefanda: hortera, friqui, moñas, bicho raro, empanado, cani, choni, boomer, pringado...

\footnotetext{
22 "La parole adolescente, orale, écrite, peut apparaître comme un acte saturé d'affects".
} 
Como acaba ocurriendo en estos casos, algunos de estos insultos se reivindican por el agraviado y se invierte su carga negativa:

6. Yo nunca he sido más que un bicho raro (https://twitter.com/search?lang=es\&q=bicho\%2 oraro\&src=typed_query).

7. Mi padre lleva hoy una camisa super hortera. Me la tiene que dejar (https://twitter.com/C oreySeixx/status/1377948611208753156).

Las emociones también están detrás del orden de palabras, inclinando este, en la tensión que siempre lo afecta, hacia lo pragmático (Padilla 2001: 189-192). (8) y (9) son ejemplos claros de esa sintaxis centrífuga, parcelada o concatenada, característica del coloquio (Mancera 2009: 87-88):

8. Oye yo es que eso no me ha quedado nada claro (corpus de Diego Gibanel, estudiantes de 2. ${ }^{\circ}$ del grado de Estudios Hispánicos de la Universidad de Alcalá)

9. A: - ¿Cómo fue la tarde con la chavala?

B: - Pues bien. A ver. Me fui sin despedirme no darle dos besos. Por que saber llevar todo...Es complicado. Estuve enseñándole y ayudándole. Lo único fue que eso...pues no lo hice, tampoco quiero tener mucho acercamiento. Si no es más que eso. De hecho, le he dicho de estudiar mejor por videollamada (wasap B: varón 20 años).

El adolescente es un ser que necesita mucho del apoyo de los suyos, de modo que busca continuamente crear un clima de complicidad con su destinatario. Para tal función están los característicos vocativos empleados para el control conversacional, tan sujetos a renovación: macho, colega, tío, tronco..., o los americanos flaco (Argentina), marico/a, huevón, vale... (Colombia), mae (Costa Rica), puro (Cuba), güey (México), chamo/a, pana, marico/a $(\text { Venezuela })^{23} \ldots$ Fruto de esta sociabilidad, los adolescentes pasan mucho tiempo hablando entre ellos, a veces, sin tener nada especial que decir. Esto los lleva al juego manierista de retorcer temas y palabras ordinarias, dando lugar a formaciones humorísticas, que, una vez perdido su efecto, desaparecen. Tal comportamiento lleva a Halliday (1998 [1978]: 215) a destacar también la orientación textual de la variedad adolescente y de otros grupos minoritarios. En su compilación del argot juvenil madrileño, E. Cianca y E. Gavilanes (2018: 148) mencionan expresiones rimadas sin referencia alguna (la polla con cebolla, la polla de Troya, estar más pedo que Alfredo, más a gusto que un arbusto, feliz como una perdiz, gay sin ley, ser un pipa de

\footnotetext{
${ }^{23}$ Hemos observado en tuits de origen chileno mucho empleo de colega. Carecemos de más datos para elevar este hecho a categoría.
} 
La Elipa, un truño como un puño... $)^{24}$ o desautomatizaciones: ya ves truz (ya ves tú), ¿cómo andamios? (por ¿cómo andamos?) ...

\subsection{El medio es el mensaje: las redes sociales}

El aforismo de M. McLuhan, título del capítulo primero de su libro Understanding Media: The Extensions of Man (1964), "el medio es el mensaje", ha cobrado una actualidad indudable con las redes sociales y, en general, con la comunicación por Internet. Las redes sociales, concebidas como medio, determinan los mensajes y, como componente de ellos, su lengua. El caso más evidente es el de Twitter, cuyos mensajes no pueden exceder los 280 caracteres, obligando a una concisión extrema que no es privativa solo de ella. Había que ser concisos en los SMS, por motivos económicos; y hay que serlo por eficiencia comunicativa en las otras redes, aunque no existan limitaciones en el número de caracteres.

Esta brevedad conecta con el uso desaforado de abreviaturas, bastantes onomatopéyicas. Una abreviatura muy usada hoy es $K l k$, de ¿qué es lo que hay?, quizá de origen dominicano, como fórmula de saludo:

10. Otros 7 meses para sacar el mapa o klk (https://twitter.com/EsmeraldaLudmi).

11. Y klk esta gente to' lo día en una sala (https://twitter.com/yaatusabeeee/status/1377427092 036411393).

Prueba de su extensión es que el saludo se sustantiva en algunos casos:

12. Por segunda vez lo gano y mi KLK solo está en $V$, quisiera verlo cuando esté en $X$ @MKMobileGame (https://twitter.com/search?lang=es\&q=\%22Klk\%22\&src=typed_query).

Sea o no cierto que la fórmula Klk surge en la República Dominicana, las redes sociales han sido clave en la difusión de las novedades adolescentes, lingüísticas y culturales. Posiblemente, la expresión (es)tá to Gucci cruzó el Atlántico desde España gracias a las redes sociales. Aquí hay un ejemplo que parece ser de un usuario colombiano:

13. To gucci, to padra mucho ánimo sumerce usted puede (https://twitter.com/OfCampo/sta tus/1378921618748149760).

Trasladados al ámbito temático, una de las grandes novedades, y razón de su fortaleza, de las redes es la posibilidad, antes privativa de unos pocos, que ofrecen a sus usuarios de

\footnotetext{
${ }^{24}$ A ellas puede añadirse alguna otra, como Rambo en el pecho del jambo, cuyo origen parece estar en una canción de YouTube. "Rambo en el pecho del jambo es el único rambo que conozco JAJSJWJABAJAJ" (https://twitter.com/luucia275/status/1378768988126199808).
} 
formarse una imagen mediante la exhibición de aspectos de su vida que pretenden interesantes. Así piensan construir una imagen ideal, más ajustada al avatar elegido, que al propio ser. Tal situación ha dado lugar a la paradoja de que, en una sociedad en la que la privacidad es un bien jurídico muy protegido, infinidad de personas, adolescentes o no, ponen en circulación desinhibidamente por las redes una intimidad que es ya extimidad ${ }^{25}$. Volveremos sobre esta cuestión más abajo en \$3.2.

Las redes han despertado mucha atención y no solo por la determinación de los mensajes y de su lengua, causa de una auténtica brecha generacional en lo que a comunicación se refiere. Las redes se han convertido en el escenario habitual de comunicación entre los adolescentes, complementando, si no, desplazando, la interacción oral, presencial, libre de la tutela adulta, del patio del colegio, parques, centros comerciales. Así, las redes se han convertido en el espacio ideal para el desarrollo, renovación e identificación de la lengua de los adolescentes como variedad propia del español, social y estilística. Así las redes, y esto nos interesa también, se han convertido en el espacio en el que muchos adolescentes se sienten alguien o pueden sentirse alguien. Ahí está delante de sus ojos el modelo de los influencers, personas normales convertidas en famosas gracias a las redes ${ }^{26}$.

\section{Estilo comunicativo y estilo de vida adolescentes}

Descrito el estilo comunicativo adolescente con cierto detalle, nos asaltan dos preguntas, la primera de las cuales ya ha aparecido en estas líneas:

a) ¿Qué relación tiene esta manera de hablar con la forma de pensar, por tanto, también de actuar de sus usuarios?

b) Si se modifica esta manera de hablar, ¿puede modificarse la conducta de los adolescentes?

Responderemos a estas preguntas, a la primera, en este apartado, y a la segunda, en el siguiente. Lo haremos desde nuestras intuiciones, lecturas y experiencia con adolescentes, sin

\footnotetext{
${ }^{25}$ Término proveniente de J. Lacan, que define S. Tisseron (2011: 84) como "el proceso por el cual unos fragmentos del sí íntimo se propone a la mirada del otro para ser validados" ("Le processus par lequel des fragments du soi intime sont proposés au regard d'autrui afin d'être validés").

26 "-Las redes sociales son la cumbre de la apariencia. -Son el símbolo del narcisismo. Pero, ¿cómo acaba Narciso? Ahogado en el lago. Se gusta, pero no se ama, y en las redes se ve a gente que se quiere gustar porque no se ama" ("El $20 \%$ de la gente cambiará por convicción y empujará al 80\% restante", Entrevista a Álex Rovira, El diario vasco, 23/08/2020).
} 
pretender dar algo más que buenas razones. El postulado de partida será que el uso de una lengua es una faceta de la conducta humana y el estilo comunicativo es parte de un estilo de $\operatorname{vida}^{27}$ que se manifiesta también en las preferencias en vestimenta, gestos y posturas, música... (Irvine 2001: 23).

La relación entre estilo comunicativo y estilo de vida es posible porque, con todas las reservas que se quiera, existe un núcleo personal desde el que se explican todos sus actos. Esto nos lleva a la vieja afirmación de Georges-Louis Leclerc, conde de Buffon, de que "el estilo es el hombre mismo" (Le style est l'homme même). La cita tiene su razón: la forma de hablar de los adolescentes es consecuencia, no necesariamente directa, de una forma de ser y de vivir. Detrás de esa expresión cotidiana de desaprobación de "No me gusta ese chico/a", está su lengua.

Hemos hablado de responder con buenas razones, porque demostrar que el estilo comunicativo adolescente es parte de su estilo de vida es demasiada tarea de cuya complejidad puede dar una idea el excelente Blanco Salgueiro (2017) sobre la relatividad lingüística. Seguiremos diciendo algo, no obstante, desde el supuesto de un impacto de doble sentido entre estilo comunicativo y de vida, de modo que los cambios en uno son también cambios en el otro. No tenemos ninguna razón para dar preeminencia a uno de los dos estilos sobre el otro, el estilo comunicativo es parte del estilo de vida de una persona o de un grupo.

\subsection{Lenguaje formulaico, usos sociales y tópicos}

Que la manera de hablar adolescente es una conducta, una forma de vida que diríamos utilizando el problemático término de Wittgenstein (Marrades 2014), se observa especialmente a través de su lenguaje formulaico. Tal como se entiende en investigaciones próximas a la Gramática de construcciones (p. ej. Wood 2015), el lenguaje formulaico se refiere a esas secuencias de palabras - multi-word sequences- que aparecen en las producciones orales y escritas y que el hablante, nativo o no nativo, almacena de forma holística, es decir, como un conjunto (Escanilla Martínez 2020: 22).

Los ejemplos que pueden aducirse de este lenguaje formulaico, donde se entienden las fórmulas en un sentido más amplio que en Fraseología ${ }^{28}$, son muy numerosos. Veamos

\footnotetext{
${ }^{27}$ Jung y, sobre todo, Adler, discípulos ambos de Freud, acuñaron el concepto de estilo de vida para designar "la unicidad del individuo, la unidad de su personalidad, su forma característica de comportamiento, la intencionalidad de sus esfuerzos y su lucha creativa por superar las inferioridades personales y los impedimentos del ambiente" (Nawas 1971: 93).

${ }^{28}$ Una fórmula para el lenguaje formulaico es una "cadena de palabra que es usada a menudo" (a word string which is used often. Cursiva en el original), con "un significado o función unitarios" (a unitary meaning or function) y
} 
algunos de estos bloques prefabricados que responden a un esquema, que funcionan en un esquema mayor y parecen ser más representativamente adolescentes, tanto que algunos de ellos sirven para caricaturizar su forma de hablar destacándose su pobreza expresiva. Nos hemos fijado solo en unos usos recientes, desde luego, más que otros más antiguos, como los bien estudiados vale y venga (Caballero 2018$)^{29}$.

De ni tan mal señala Irene Daie Pintado, estudiante de $1 .^{\circ}$ de grado de Estudios Hispánicos de la Universidad de Alcalá, curso 2020-2021 que:

A pesar de existir desde hace ya bastante tiempo, la muletilla 'ni tan mal' ha sido muy empleada estos últimos años, sobre todo, entre los jóvenes. Sin embargo, como con todas las muletillas, no es recomendado abusar de su uso. Las expresiones formadas por 'ni tan + adverbio' se emplean de manera coloquial para referirnos a lo contrario de lo que se ha dicho ('ni tan alto' equivale así pues a que es relativamente bajo). En Cianca y Gavilanes (2018: 168) se define su significado como "se emplea cuando se presenta o se ofrece algo que no se esperaba y que viene bien". Así pues, la oración "Pensaba que iba a hacer más calor, pero ni tan mal" quiere decir que, de haber sido así, no hubiera pasado nada, pero que es mejor que sea así. Un significado equivalente sería 'No voy a decir que no'.

¿Sí o qué? es "una fórmula que realmente no es una pregunta, sino una petición de confirmación" (Cianca y Gavilanes 2018: 164). La mayoría de los ejemplos que hemos encontrado en Twitter son de América. Con las debidas cautelas con que hay que tomar las identidades en las redes sociales, (14) es de una muchacha de Costa Rica y (15), de un joven argentino, por lo que sería una prueba más de que las modas no se paran ante el océano:

14. ¿Todos estamos bajoneados hoy sí o que? (https://twitter.com/ValeAlpzar1/status/1372396 363439341568).

15. ¿Me caso con una porteña sí o que?? (https://twitter.com/BraianAndrade18)

Esta fórmula parece haber desplazado las anteriores ¿sí, verdad?, ¿sí, no?, aunque no sabemos si incorpora el frecuente componente irónico de estas.

Ya ves es otro ejemplo. De ella da la siguiente información Andrea Lorenzo ( $3 .^{\circ}$ grado de Lenguas Modernas y Traducción, Alcalá, 2017-2018): "en vez de afirmar o negar algo

\footnotetext{
"quizá [con] una manera particular de ser mentalmente almacenada, recuperada o producida también (perhaps a particular way of being mentally stored, retrieved, or produced as well) (Wood 2005: 20).

${ }^{29}$ En la prensa aparecen con cierta frecuencia artículos o reportajes sobre la lengua de los adolescentes donde se recogen algunas de estas fórmulas: E. Sánchez (2015); R. Vallés (2018); M. Camps (2019); https://www.elperiodico.com/es/cuaderno/20190706/en-plan-crush-putoflipa-diccionario-de-argotadolescente-7538640.
} 
contestamos con esta expresión. Ejemplo: Ya ves, tío". La etapa final de estas fórmulas es su sustantivación como en

16. No no noo, no me compares con nadie mi amor. No me parezco a ninguno ya ves. Yo soy lo más lindo de papá y mamáa (https://twitter.com/mapso812/status/137614964297977446 5).

Ya ves recuerda a las anteriores ya te digo y además, de verdad:

17. Españolas hoy dormimos una hora menos.

Ya te digo pero aquí estamos \#senbenimdünyamsin

ya te digo?, o quieres que me espere? (https://twitter.com/search?lang=es\&q=\%22ya\%20t e\%20digo\%22\&src=typed_query).

18. Abrázame hasta que dejen de dudar de si quitan o ponen la vacuna de Astrazeneca. Pero además de verdad, que hoy me hace mucha falta (https://twitter.com/AnagLisa/status/13 80189190650916866).

Otra fórmula actual en el momento en que se escriben estas líneas es estás que. Tiene un carácter irónico, pues niega categóricamente lo que afirma o afirma categóricamente lo que niega. Como en otros usos metarrepresentacionales (p. ej. las interrogativas de este nombre, Escandell 2000), tal efecto se logra por el contraste, expresado por medio de una sintaxis simplificada, entre la decisión firme del hablante y el pensamiento del otro (estás por):

19. Retraso cada mañana el despertador para dormir un poco más y me voy a levantar a las seis UN DOMINGO para irme de pijameo, estas que sí (https://twitter.com/iratxeAG/status/1 $\underline{376840906318479363)}$.

20. ¿Y TE PIENSAS QUE NO LEERLO VAS A DEJAR DE SUFRIR? ESTÁS QUE SI COMPAÑERA (https://twitter.com/misxntropia/status/1376205391932047363).

21. Yo lo he cancelado ya, estás que pago $10 €$ al mes por algo que se ve peor que gratis (https://twitter.com/search?lang=es\&q=\%22estás\%20que\%20pago\%22\&src=typed_. query).

22. Yo si lo hago, lo hago con mucha gente estas que lo hago solo (https://twitter.com/o6Dyx/ status/1377041083876700161).

(19) niega categóricamente que vaya a irse de pijameo ('madrugar para acudir en pijama al bar'); (20), que dejar de leerlo vaya a ahorrar sufrimiento; (21), que vaya a pagar; y (22), que 
esté dispuesto a hacerlo solo ${ }^{30}$. La función de la fórmula recuerda las anteriores Estás tú bueno o Lo tienes claro.

En las manifestaciones orales adolescentes, aparece una y otra vez y nada para cerrar como fácil recurso cualquier miembro de una secuencia narrativa. Ponemos estos ejemplos tomados del corpus Cola (http://korpus.uib.no/cgi-bin/cola/cqp-cola):

23. <p MAORE2JO2-> I[me dice] < p MAORE2JO2-> y y y mmm y nada bueno entonces nos vamos y nada le dice le dice a @nombre e

24. MABPE2Jo2 - + tal bueno voy a coger el ciento treinta y dos y nada cojo me subo <orig norm="todo" $>$ to $<$ /orig $>$ bien pam me voy

25. MAORE2J02 - + @nombre.. y y y y nada fuímos a casa y nada cuando llegamos allí /. nada nos pusimos el pijama /

26. MAORE2JO2 - + je <p MAORE2JO2-> y bueno y nada y luego ya se fue y nada cuando llegó nos dijoo hola guapetonas no sé qué tal no sé

27. MAORE2JO2 - + se qué entonces se encontró al @nombre y y y y nada de repente empiezaaaa empieza@nombre@nombre@nombre ven

28. MAESB2JO1 - + albergue por ahí en un refugio pues nos encontramos y nada empezamos a hablar y tal lo que pasa es que estabamos

Como palabras de la tribu, por utilizar una feliz expresión de J. Á. Valente (1971), las fórmulas son usos sociales (Wood 2015: 5-6). Acerca de la importancia de estos dice Ortega y Gasset (2004: 756):

Jamás ha acontecido ni acontecerá que el hombre pueda conducirse exclusivamente según su personal gobierno. Una criatura humana en cuya existencia no tuviesen la menor intervención los usos, costumbres y leyes no podría sostenerse porque ello implicaría tener que inventar en absoluto [...] todos sus pensamientos, deseos y medios de satisfacerlos.

Estas fórmulas y expresiones idiomáticas son, pues, formas del comportamiento social. Desde la etología humana del austriaco I. Eibl-Eibesfeldt, que postula el "alto grado de ritualización del comportamiento hablado" (Eibl-Eibesfeldt, citado por Olímpio de Oliveira 2015: 162), se han estudiado las frecuentes relaciones entre la comunicación no verbal y verbal, camino del mayor interés que cuenta con el precedente de Martinell, Forment y Vallés (2002). Pero la etología no se queda aquí, sino que va más lejos, indaga sobre las bases universales y

\footnotetext{
${ }^{30}$ Debo esta información a Rubén Burgos ( $3 .{ }^{\circ}$ del grado de Estudios Hispánicos de la Universidad de Alcalá) y a Mayte Molina (Máster Universitario en Formación de Profesores de Español de la Universidad de Alcalá).
} 
culturales de tales relaciones (Olímpio de Oliveira 2015: 159-161). De haber vivido, el gran E. Goffman habría visto muchas de estas fórmulas como ejemplo de esos ritos que organizan la convivencia (Portolés 2011/2012: 227-228, 229-230).

Un segundo aspecto de estas fórmulas, que algunos califican despectivamente con el término psiquiátrico de psitacismos ('habla de loros') (Dufour y Amorim 2009) y que estamos estudiando como usos sociales, es su carácter también de tópicos. En su blog, Se me va de la lengua (http://www.semevadelalengua.es/?p=655), C. de Benito, gran estudiosa de la lengua de los tuits, ha recopilado un número significativo de las construcciones más habituales en estos (¿Qué edad/cuántos años tenías cuando/a qué edad descubriste?/¿Qué es un...?/ ¿Qué hago, X? ¿Me mato? / ¿Quieres noséqué? Quiéralo mucho, mándele cartitas de amor...) (https://docs. google.com/spreadsheets/d/1hkbAFhmCa-WKpooV5F6UCYCRUpJYO14dlLfFA1vgqh4/edit\#gid=0) ${ }^{31}$.

No nos parecen construcciones específicamente de adolescentes, quizá apenas las usen, dada la presumible franja de edad de los informantes en que se ha basado la investigadora para componer este corpus. Sea como sea, se observa en este listado, del que solo hemos tomado unos pocos ejemplos, un aspecto muy propio del estilo comunicativo adolescente, desde luego cuando usan las redes: la comunicación es entre conocidos que comparten una manera de entender la vida, por tanto, no es necesario andarse con formalidades ni con explicaciones. En este mundo, en el que existe mucho miedo a exponerse y que te etiqueten, las redes sociales sirven de refugio para hablar con libertad. El secreto está en lo que C. de Benito dice muy bien en el mencionado blog:

las características lingüísticas de gran parte de lo que se escribe en Twitter son propias del habla coloquial: ¿por qué? Mi hipótesis es que, puesto que los usuarios pronto crean sus propios grupos de conocidos y amistades, incluso cuando entras en contacto con alguien desconocido no es raro que sea "amigo de amigo". Tengo otra hipótesis además: precisamente el uso de estrategias propias del habla coloquial ayuda a entrar en contacto con personas desconocidas, como instrumento para demostrar buena intención y cortesía (sí, en Twitter hay mucho odio, pero desde luego no es lo único) al entablar una nueva conversación.

\footnotetext{
${ }^{31} \mathrm{C}$. de Benito, en su blog (http://www.semevadelalengua.es/?p=655), anota la diversidad estructural de estas construcciones: "Las construcciones repetidas pueden tener niveles de abstracción muy distintos. Encontramos desde frases que se reproducen palabra por palabra hasta patrones totalmente abiertos, pasando por estructuras que tienen un fragmento que se repite de forma literal pero que tienen un "hueco" abierto que cada uno rellena con material propio".
} 


\subsection{La búsqueda de la identidad en el adolescente}

Como señalábamos al principio, sobre el adolescente se agolpan las descalificaciones: inmaduro, adicto a las nuevas tecnologías y, por tanto, superficial ${ }^{32}$, sin fortaleza de carácter, hedonista, indisciplinado, esclavo de las modas... La parte de verdad que encierran estos tópicos no autoriza a creer que la mente adolescente sea lineal y elemental. No puede ser, porque muchos adolescentes no son así; en el fondo, ninguno es un ejemplo perfecto de este estereotipo, porque siempre está el individuo. Indicio de la complejidad de la mente adolescente es la impronta metarrepresentacional de muchos de sus enunciados (\$2.3). Bien es verdad que la metarrepresentatividad se hace presente, a través, a menudo, de fórmulas convencionalizadas, por tanto, bastante automáticas; pero bien es verdad, igualmente, que, incluso, a través de tales fórmulas, emerge el análisis, propio y ajeno, del mundo interior.

Lo que vamos a hacer en este subapartado es suspender el juicio que implica esta caricatura para fijarnos en la preocupación adolescente por la identidad, preocupación que se plasma en cuestiones concretas como el deseo de ser aceptado y respetado por los demás o la curiosidad por saber cómo se es visto por ellos. La cuestión de la identidad es clave para entender los estilos comunicativos y de vida adolescentes.

\subsubsection{Identidad e imagen}

Todos aspiramos a ser queridos, valorados, acogidos..., así como a que se respete nuestra autonomía personal. En lo que se refiere a la primera parte de estos deseos, ser querido, valorado..., se trata de un deseo fuertemente individual, en gran medida, exclusivista. Para satisfacerlo, necesitamos una identidad como beneficiaria de lo que ese deseo reclama de los demás y, al mismo tiempo, como atractora de estos, pues solo los demás pueden atender esa aspiración de ser querido, valorado y acogido. Lo malo es que los demás no van a colmar simplemente porque nosotros abriguemos estas aspiraciones, lo malo es que, también, los demás albergan estos mismos deseos respecto a sí mismos, deseos que hemos caracterizado como individualistas y exclusivistas.

\footnotetext{
${ }^{32}$ Este es un juicio que se extiende a todos los usuarios de Internet, prototípicamente los jóvenes y los adolescentes. Son muy citadas estas demoledoras palabras de $\mathrm{M}$. Vargas Llosa, pronunciadas en una entrevista a la revista uruguaya Búsqueda en 2011: "El Internet ha acabado con la gramática, ha liquidado la gramática. De modo que se vive una especie de barbarie sintáctica [...]. Si escribes así, es que hablas así; si hablas así, es que piensas así y si piensas así, es que piensas como un mono [...]. Tal vez la gente sea más feliz si llega a ese estado. Quizás los monos son más felices que los seres humanos (M. Vargas-Llosa)" (https://www.andacol.com/index.php/71-revista-anda/revista-anda-45/373-mario-vargas-llosa-comentasobre-la-decadencia-de-los-medios). No es Vargas Llosa el único en hablar de barbarie con respecto a esta manera de comunicar, lo veremos un poco más abajo.
} 
La identidad como yo es un hecho primario con el que se encuentra cualquier persona desde muy pronto, pero irrumpe con fuerza pasada la infancia. Sin embargo, marcada la persona por un sentimiento de inferioridad constitutivo, ese yo que ha descubierto, que empieza a tener una historia, no le sirve, no le gusta, no confía en él, aunque tampoco puede eliminarlo, porque nadie puede ahogar completamente la realidad de un yo que está ahí. Es preciso mejorar esa identidad, pero no de cualquier modo, pues construirse una identidad nueva tampoco es la solución, si esa nueva identidad es una traición a la identidad primaria, al yo, fuente siempre y, al mismo tiempo, destino de los deseos de los que está hablándose.

Ante tal estado de cosas, algunos, en pos de la autenticidad personal, dan un paso más en el camino hacia el yo verdadero, que es también su mejor yo, en la línea de Píndaro o Nietzsche, de llegar a ser quien se es (Manzano Arzate 2010). Las etapas de este proceso de autoidentificación podrían representarse, respectivamente, primero, como, ser algo, luego, ser alguien y, finalmente, ser uno mismo. Todo menos quedarse en un don nadie ${ }^{33}$.

\subsubsection{La identidad en el adolescente}

En el adolescente, la tensión entre los deseos de los que está hablándose $\mathrm{e}^{34} \mathrm{y}$ la necesidad de contar con una identidad para satisfacerlos es particularmente acusada. Su solución o, al menos, su atenuación, en los términos que está planteándose la tensión, es tarea de una vida, solo llega con la madurez. Mientras, el adolescente tiene que ir formándose, decidiendo hacia donde quiere orientar su respuesta: hacia la soledad del lobo estepario, sin renunciar a su yo, o hacia la acomodación a los requerimientos ajenos, tapando su identidad con una máscara protectora, con una imagen (face) como se le conoce desde E. Goffman y los estudios de la cortesía (cf. Portolés 2011/2012: 225-230). Cuanto más inseguro se sienta el adolescente, más tupida será esa máscara, más se aferrará a ella.

No estamos ante un problema filosófico, sino ante la angustia existencial del adolescente, motivada por la fuerza de unas necesidades afectivas que pasan por una mayor individuación, que lo empujan a diferenciarse para ser él, en primer lugar, de su familia. Junto a ellas, al mismo tiempo, el deseo de conocerse y la búsqueda del reconocimiento y valoración ajenos, porque somos como nos ven los demás ${ }^{35}$. Esto lo siente el adolescente, de ahí su

\footnotetext{
${ }^{33}$ Para la relación entre identidad, en muy diversos aspectos, y lengua es imprescindible el reciente F. Moreno Fernández (2020).

${ }^{34}$ A ellos se refiere Wang (2020: 48-49) como interdeseos de afiliación, autonomía y estatus. La razón de esa denominación se halla en que los interdeseos son un "deseo social interpersonal" (Wang 2020: 48).

${ }^{35}$ Para entender lo que está diciéndose, recomendamos la lectura de lo escrito por Sartre acerca de la mirada ajena (Cf. Pertseva 2017).
} 
sensibilidad al desprecio (Horney 1981 [1937]: capítulo 8). Finalmente, esta realidad tan compleja desemboca en esa dialéctica ya mencionada entre ser uno mismo o plegarse a los demás. En tal lucha de fuerzas opuestas han situado el origen de las neurosis psicoanalistas como K. Horney (1981 [1937]).

La necesidad de individualización de la que está hablándose explica la bien conocida atracción adolescente, tradicionalmente, masculina (Zimmermann 2005: 252), por la extravagancia, por ejemplo, por lo friki, o directamente por la transgresión (delincuencia, drogadicción...), que sitúa a bastantes adolescentes "en una periferia marginal". En los casos extremos, el destino de tal atracción es la pandilla, la banda o mara; en los casos más normales, para situarse en la marginalidad solo "de forma ficticia y provisional", quizá formando parte de una tribu urbana. Y es que muchos adolescentes solo "se separan en determinados momentos (los fines de semana) y terminan por incorporarse a la posición que les corresponde en la sociedad tradicional (familia, escuela o trabajo)" (Molina 2010: 200-201). En cualquier caso, se comprende bien que la variedad adolescente tome del discurso de la marginalidad:

la degradación semántica; el tono irónico o humorístico ${ }^{36}$; la expresión directa y su correspondiente ausencia de eufemismos; una fuerte inclinación al disfemismo y a las palabras malsonantes y, en general, la intensificación de la cualidad y de la cantidad con expresiones innovadoras (Molina 2010: 201-202).

No es fácil sintetizarlo mejor ${ }^{37}$.

Tal estado de cosas ha llevado a autores como Halliday (1998 [1978]: 222) a relacionar la variedad estudiantil, por tanto, adolescente, con los antilenguajes, esto es, con la lengua de las antisociedades, una de cuyas manifestaciones es la anticortesía, donde las groserías, los insultos y otras expresiones ofensivas son sin ánimo de ofender, porque en los contextos donde se da la anticortesía no hay un deseo de respetar la imagen/identidad personal, sino de denigración (Zimmermann 2005: 249). Ese empleo de insultos contra sus interlocutores, de expresiones fuertes y groseras, en general, persigue paradójicamente en algunos no solo la diferenciación, aunque sea por vía negativa, sino incluso la construcción de una imagen positiva, dentro de

\footnotetext{
${ }^{36}$ La tendencia a reírse del otro, a ponerle apodos, a ridiculizarlo, ha sido tradicionalmente más propia de los preadolescentes varones (cf. Mamajón 2014: 26).

${ }^{37}$ No obstante, siempre hay que evitar las generalizaciones. Cianca y Gavilanes (2018: 149) anotan el grupo que constituyen unas palabras acabadas en -i (besis, guapi, holi, okis) "que se emplean para dar un tono más cariñoso y familiar a la conversación", especialmente, por parte de chicas. Este hecho debe compatibilizarse con la incorporación plena al habla femenina del léxico vulgar (Molina 2010: 212-213).
} 
un sistema de valores en los que sobresalen la brutalidad, la arrogancia, la violencia en todos los órdenes y similares, y la lealtad al grupo.

Esto es así porque la identidad que se busca no se liga a una imagen positiva personal, sino a una imagen grupal construida por medio de esa forma de hablar diferenciada de la que marcan los valores y las convenciones dominantes en la sociedad. Ya se sabe que la variedad adolescente tiene como función mucho más fortalecer el grupo, crear lazos estrechos entre sus miembros que comunicar o pensar (ver, arriba, \$2.5). Lógicamente, esta motivación inicial puede ser en muchos adolescentes un hábito más bien inocente, explicable como una acomodación sin más al ambiente. Como les sucede a los adolescentes colombianos, de ambos sexos, que se tratan con toda normalidad de huevón/a, hijoputa o marico/a con toda naturalidad. Es una práctica común de la que da testimonio una joven estudiante española de máster: "desde mi propia experiencia, en un contexto informal y distendido con amigos no tendría problema en usar ciertas expresiones e incluso insultos (sin intención de ofender la mayoría de las veces, aunque pueda sonar contradictorio)" ${ }^{38}$.

Resumiendo, aunque la lengua adolescente no funciona necesariamente siempre como un antilenguaje, sí parece que en esta variedad funciona de modo bastante mayoritario el prestigio encubierto de lo antinormativo, propio de los grupos que se constituyen al margen o en contra de la sociedad establecida (Silva-Corvalán y Enrique-Arias 2017: \$4.3.3).

\section{4. ¿Qué hacer?}

La Lingüística ha rebasado los estrechos límites en que la enmarcaron estructuralistas y generativistas, de la mano del dogma saussureano de que la Lingüística es descriptiva y explicativa, no prescriptiva como la gramática tradicional ${ }^{39}$. La superación de esta línea roja

\footnotetext{
${ }^{38}$ Los jóvenes de Santiago de Chile se tratan entre sí normalmente de huevón/a, loco/a, culi(e)ado/a, mina o maricón (Jørgensen y Arli 2012).

${ }^{39}$ Una de las mayores figuras del estructuralismo europeo, A. Martinet (1960: 6) escribió: "La lingüística es el estudio científico de la lengua humana. Un estudio es científico cuando se basa en la observación de los hechos y se abstiene de proponer una elección entre estos hechos en nombre de ciertos principios estéticos o morales. Por lo tanto, "científico" se opone a lo "prescriptivo". En el caso de la lingüística, es particularmente importante destacar la naturaleza científica y no prescriptiva del estudio: el objeto de esta ciencia, que es una actividad humana, la tentación es grande de abandonar el campo de la observación imparcial para recomendar un determinado comportamiento, ya no tener en cuenta lo que realmente se dice, sino promulgar lo que hay que decir" ("La linguistique est l'étude scientifique du langage humain. Une étude est dite scientifique lorsqu'elle se fonde sur l'observation des faits et s'abstient de proposer un choix parmi ces faits au nom de certains principes esthétiques ou moraux. "Scientifique "s'oppose donc à " prescriptif ". Dans le cas de la linguistique, il est particulièrement important d'insister sur le caractère scientifique et non prescriptif de l'étude : l'objet de cette science étant une activité humaine, la tentation est grande de quitter le domaine de l'observation impartiale pour
} 
ha permitido a los lingüistas aplicarse a la solución de problemas individuales y sociales, de modo que son legión los lingüistas interesados hoy por la corrección idiomática, la redacción de textos y la política lingüista, al servicio esta de la ingeniería social.

En este ámbito de la Lingüística aplicada, se produce el trabajo del profesor de Lengua y Literatura de Primaria y Secundaria. Su tarea principal se centra en el desarrollo de la competencia en comunicación lingüística de sus alumnos, en cuya dimensión existencial (saber ser) está el "ser consciente de la repercusión de la lengua en otras personas" (Ministerio de Educación y Formación Profesional s. d.) y también, añadimos, en uno mismo.

Pensando en este cometido del profesor de Lengua y Literatura, la manera de hablar de sus estudiantes no le puede ser ajena, pues es una base excelente para hacerles pensar acerca de la relación entre cómo se habla, cómo se piensa y cómo se vive. Tal conexión está muy clara en la controvertida tesis del sociólogo británico Bernstein $(1975: 31,39)$ o en el pensamiento de C. Ladjali, autora con G. Steiner del precioso Elogio de la transmisión (Steiner y Ladjali 2005 [2003]) ${ }^{40}$. Esta investigadora, docente de Secundaria, sostiene que "la enfermedad de la juventud es que cada vez menos está en posesión de una sintaxis, de un vocabulario rico y variado... El barbarismo prefigura la barbarie" (Ladjali 2007: 11 y 12) ${ }^{41}$. A ello añade unas palabras que no pueden dejar indiferente: "El no-lenguaje, el vacío, se convierten rápidamente en ontología [...]. La de la falsa identidad que ellos van a intentar imponer a los otros y a ellos mismos" (2007: 23-24) ${ }^{42}$.

Inspirados en este análisis, Dufour y Amorim (2009) señalan que "la destrucción de la gramática de la lengua antigua", operada en la nueva lengua surgida de las redes y, en general, en estos nuevos usos, ha dado lugar a "una lengua única, que se corresponde con el pensamiento único, que es propio del mundo contemporáneo, en cuyo interior el adolescente

recommander un certain comportement, de ne plus noter ce qu'on dit réellement, mais d'édicter ce qu'il faut dire").

${ }^{40}$ La valoración de la variedad adolescente es motivo de una polémica muy dependiente de la ideología de los participantes. Arditty y Blanchet (2008) y Dufour y Amorim (2009) son ejemplos de las dos posturas contrapuestas. Como no se oculta, nuestro discurso se alinea entre los que ven peligros en el estilo adolescente, primero, porque es lo que nos impone la realidad, segundo, porque es el medio para proponer al adolescente algo mejor, una de las obligaciones de todo educador.

${ }_{41}^{41}$ "Le malaise de la jeunesse est qu'elle est de moins en moins en possession d'une syntaxe, d'un vocabulaire riche et varié... Le barbarisme préfigure la barbarie".

42 "le non-langage, le vide, deviennent rapidement une ontologie [...]. L'expression en creux de la fausse identité qu'ils vont tenter d'imposer aux autres et à eux-mêmes, tout en sachant qu'il s'agit d'un leurre. Là réside le malheur d'une certaine jeunesse". 
queda prisionero"43. Para quien se toma en serio semejante diagnóstico, estas palabras inquietan, más cuando ya no hay reacción por parte de quienes cabría esperarla. Recordemos los versos de Gabriel y Galán del principio de estas páginas. En medio de esta complacencia, la adolescentización (ver, arriba, \$1.2) puede ser un problema más serio, algo más que una tendencia sin más en la sociedad:

El problema nace cuando estas tentativas no encuentran apenas resistencia y oposición en el universo adulto general. Cuando, justamente, estas veleidades de autonomía no pueden desempeñar su papel 'marginal' o 'rebelde' y cuando es toda la sociedad la que es 'nueva lengua'. El contacto con la cultura "adulta" a través de sus diversas manifestaciones [...], no sólo no les permite jugar su juego rebelde, sino que ya no les abre el acceso a otras posibilidades lingüísticas, estéticas y éticas para la construcción de su autonomía. Allí se forma como un lenguaje único, correspondiente al pensamiento único que es único en el mundo contemporáneo, dentro del cual el adolescente permanece encarcelado. Ahí radica una diferencia importante entre la adolescencia de ayer y la de hoy: es el mundo entero el que se ha convertido en adolescente, por lo que, los jóvenes de hoy ya no pueden encontrar a quienes enfrentarse ${ }^{44}$.

Naturalmente, a palabras tan rotundas como estas se les pueden formular múltiples objeciones; pero aquí no estamos para quedar bien ni para repetir obviedades, sino para reflexionar y hacer reflexionar sobre una realidad que nos parece evidente. Por eso, retomando el título de un famoso escrito de Lenin de 1902, ¿Qué hacer? (Chto délat?), el primer paso es proponer a los alumnos, convertidos ellos en fuente directa de información, la descripción y análisis del estilo comunicativo adolescente. El siguiente paso es la reflexión conjunta sobre la relación entre tal estilo y la conducta de sus usuarios. La eficacia de este paso dependerá de la capacidad del docente de estimular esa reflexión, mediante la ironía y la pregunta al modo socrático, y escuchar las respuestas. Es un trabajo que hay que hacer bien

\footnotetext{
43 “Un langage unique, correspondant à la pensée unique qui est le propre du monde contemporain, à l'intérieur duquel l'adolescent reste emprisonné".

44 "Le problème naît quand ces tentatives ne rencontrent plus de résistance et d'opposition dans l'univers adulte général. Quand, justement, ces velléités d'autonomie ne peuvent pas jouer leur rôle 'marginal' ou 'rebelle' et que c'est l'ensemble de la société qui se "novlanguise ". Le contact avec la culture 'adulte' à travers ses différentes manifestations [...], non seulement ne leur permet plus de jouer leur jeu rebelle, mais ne leur ouvre plus l'accès à d'autres possibilités linguistiques, esthétiques et éthiques pour la construction de l'autonomie. Il se forme là comme un langage unique, correspondant à la pensée unique qui est le propre du monde contemporain, à l'intérieur duquel l'adolescent reste emprisonné. Là réside une différence importante entre l'adolescence d'hier et celle d'aujourd'hui : c'est le monde entier qui est devenu adolescent, de sorte pour les jeunes d'aujourd'hui, qu'ils ne trouvent plus d'autre auquel s'affronter".
} 
para que tenga sentido. Tratar la lengua adolescente encierra un atractivo per se para los estudiantes y es un motivo de acercamiento a ellos, y es un medio para que ellos profundicen en las causas y consecuencias de hablar así. Sin embargo, tiene sus peligros. Uno de ellos es que todo quede en pasar un buen rato y nada más.

Para que no sea así, el profesor tiene que ser inteligente y creativo a fin de que sus alumnos descubran en esta manera de hablar:

a) las consecuencias de solo dominar esta variedad, muy limitada a las funciones de la proximidad comunicacional (ver arriba \$1.1),

b) el peligro de que el lenguaje soez de esta variedad, devenida en antilenguaje, se traslade a los actos. Y el que con el uso habitual se pierda la agresividad no impide que permanezcan los efectos de un hablar donde no cuenta el otro ni sus deseos de ser respetado, en favor de las motivaciones egoístas de divertirse y ser incluido en el grupo. El fenómeno del acoso escolar encuentra un buen caldo de cultivo en esta manera de comunicarse.

c) Los efectos de la dependencia del tipo de discurso propio de las redes sociales; y, en fin,

d) el freno que supone para llegar a ser uno mismo no desarrollar una voz propia.

$\mathrm{Al}$ adolescente hay que ponerlo ante los hechos y sus peligros, pero no es suficiente con esto. La inteligencia tiene que iluminar la voluntad y esta no se pondrá en marcha si el adolescente no lo quiere y no cree en que es capaz de superar una situación.

\section{Conclusiones}

Como cualquier otro ser humano, el adolescente se comunica en múltiples escenarios, con diversos interlocutores y sobre asuntos diferentes. Lo que se conoce como su lengua, su variedad o su estilo se circunscribe básicamente a cuando la comunicación es entre iguales en las situaciones estereotípicas en que los adolescentes interactúan. Una de estas situaciones se da en las redes sociales. Como hemos visto, los adolescentes usan de una manera muy especial en ellas la lengua. Fuera de su territorio, los adolescentes no hablan así, ni siquiera cuando lo hacen en grupo, entre ellos. Esto no quita que parece indiscutible la mutua influencia entre la lengua de la interacción oral y la lengua de las redes y otros foros de Internet.

La variedad característica de cada generación adolescente es una fuente de información del espíritu de una época y de su inserción en ella de la adolescencia. Los adultos difícilmente han dejado de fijarse en ella, por curiosidad, pero también por la inquietud ante la transgresión que encierra su estilo comunicativo. En estas páginas se ha buscado 
aprovechar la gran información existente para profundizar en la relación entre este estilo comunicativo y un estilo de vida con el que conecta de diversos modos. Tal búsqueda se ha detenido en el afán adolescente por ser él mismo, en un recorrido que comienza con la identificación grupal, frente a los adultos de referencia, y que con el tiempo puede convertirse en personal alcanzando una voz propia, como diríamos parafraseando un conocido verso de Antonio Machado (“A distinguir me paro las voces de los ecos").

Al profesor de Lengua y Literatura no le basta la observación de la variedad adolescente, ni siquiera conocerla en profundidad. No es un entomólogo que estudia la conducta de un insecto cuya suerte no le importa; tiene que ir más allá, su tarea es trabajar por que la competencia clave de la comunicación lingüística de sus estudiantes mejore y eso pasa, sin duda, porque estos no se instalen en la comodidad de una manera de hablar que les impide crecer. Para ello, hemos dado alguna idea somera, pero lo que tiene que hacer el docente es mucho más. Su materia es la lengua, con ella pensamos y nos relacionamos.

\section{Referencias bibliográficas}

Ammosy, R. y A. Herschberg Pierrot (2020): Estereotipos y clichés, Buenos Aires: EUDEBA.

Arditty, J. y Ph. Blanchet (2008): "La 'mauvaise langue' des 'ghettos linguistiques': la glottophobie française, une xénophobie qui s'ignore", Asylon(s), 4 ("Institutionnalisation de la xénophobie"). http://www.reseau-terra.eu/article748.ht $\underline{\mathrm{ml}}$

Bañón, A. (2004): "Adolescencia, variación lingüística, competencia metacomunicativa y enseñanza de la lengua", Tonos digital: Revista de estudios filológicos, 8 https:/www.um.es/glosasdidacticas/doc-es/GD12/1obanon.pdf

Battista, E. (2013): "La reconstrucción de la tradición idealista: una conferencia inédita de Amado Alonso (1940). En VI Jornadas de Filología y Lingüística, 7 al 9 de agosto de 2013, La Plata, Argentina. En Memoria Académica. http://www.memoria.fahce.unlp.edu.a $\underline{\text { r/trab_eventos/ev.4083/ev.4083.pdf }}$

Bernstein, B. (1975): Langage et classes sociales. Codes socio-linguistiques et contrôle social (trad. fr.), París: Minuit.

Blanco Salgueiro, A. (2017): La relatividad lingüística (Variaciones filosóficas), Madrid: Akal. 
Briz, A. (2003): "La interacción entre jóvenes: español coloquial, argot y lenguaje juvenil". En Echenique M. T. et al. (Coords.), Lexicografía y Lexicología en Europa y América: Homenaje a Günter Haensch, Madrid: Gredos, pp. 141-154.

Bühler, K. (1979 [1934]): Teoría del lenguaje (trad. esp.), Madrid: Alianza editorial.

Caballero, I. (2018): Estudio sociopragmático de las partículas discursivas ¡vale! y ¡venga! Trabajo final de grado dirigido por A.M. Cestero Mancera, Alcalá de Henares: Universidad de Alcalá.

Capanaga, P. y F. San Vicente (2005): “-¡Qué fuerte! -¿Siguen pasando? El lenguaje juvenil español: consolidacion de tendencias”. En Fusco, F. y C. Marcato (Eds.), Forme della comunicazione giovanile, Roma: Calamo, pp. 80-127. http://amsacta.unibo.it/5163/1/For me\%2odella\%20comunicazione\%2ogiovanile_OCR.pdf

Casas, M. (1993): “Consideraciones sobre la variación diafásica”, Pragmalingüística, 1, pp. 99124.

Catalá, M. y M. Perdomo (2017): "La innovación léxica de en plan como fórmula expresiva de los jóvenes universitarios españoles: aproximación a sus valores de uso tradicional y actual", Tonos digital: Revista de Estudios Filológicos, 33. https://digitum.um.es/digitum/ $\underline{\text { handle/10201/54017 }}$

Cianca, E. y E. Gavilanes (2018): "Voces y expresiones del argot juvenil madrileño actual", Círculo de Lingüistica Aplicada a la Comunicación, 74, pp. 147- 168. http://webs.ucm.es/in fo/circulo/no74/cianca.pdf

Coseriu, E. (1955-1956): Determinación y Entorno. Dos problemas de una lingüística del hablar, Hamburgo: De Gruyer (Romanistishes Jahrbuch VII). http://www.romling.unituebingen.de/coseriu/publi/coseriu21.pdf

Curcó, C. (2020): "Perspectivas y voces en el discurso. Metarrepresentación”. En EscandellVidal, V., J. Amenós y A. Ahern (Eds.), Pragmática, Madrid: Akal, pp. 212-233.

Daneš, F. (1966): “A three-level approach to syntax”, Travaux linguistiques de Prague, I (L'École de Prague d'aujourd'hui), pp. 225-237.

Darrault-Harris I. (2007): "S'engendrer par le langage. La parole adolescente", Enfances \& Psy, 36, pp. 41-49. https://www.cairn.info/revue-enfances-et-psy-2007-3-page-41.htm

Dufour, D.-R. y Amorim, M. (2009): “Langage et adolescence”, Adolescence, 27 (4), pp. 941-957. https://www.cairn.info/revue-adolescence-2009-4-page-941.htm\#pa3 
Escandell, M. V. (1994): “La noción de 'estilo' en la Teoría de la Relevancia”. En Dehennin, E. y H. Haverkate (Dirs.), Lingüística y Estilística de texto, Ámsterdam/Atlanta, GA, pp. 55-64.

Escandell, M. V. (2000): "Sintaxis y uso interpretativo". En Korta, K. y F. García Murga (comp.): Palabras. Víctor Sánchez de Zavala in memoriam, Bilbao: Servicio Editorial de la Universidad del País Vasco, pp. 219-259.

Escanilla Martínez, I. (2020): El lenguaje formulaico y su importancia en la adquisición/aprendizaje de segundas lenguas. Trabajo Final de Máster dirigido por M. Martí Sánchez, Alcalá: Universidad de Alcalá.

Fábregas, A. (2013): La morfología. El análisis de la palabra compleja. Madrid: Síntesis.

García Serrano, R. (1964): Diccionario para un macuto, Madrid: Editora Nacional.

Goddard, Cl. y A. Wierzbicka (1997): Discourse and Culture. En van Dijk, T. A. (ed.): Discourse as Social Interaction, London: Sage Publications, pp. 231-259.

Halliday, M.A.K. (1998 [1978]): El lenguaje como semiótica social. La interpretación social del lenguaje y del significado (trad. esp.), Bogotá: Fondo de Cultura Económica.

Hernández, I. y A. M. ${ }^{a}$ Vigara, (2007): "El lenguaje coloquial juvenil en la publicidad de radio y televisión", Revista de Estudios de Juventud, 78, pp. 141-160.

Irvine J. T. (2001): “Style' as distinctiveness The culture and ideology of linguistic differentiation". En Eckert, P. y J. Rickford (Eds.), Style and sociolinguistic variation, Cambridge: Cambridge University Press, pp. 21-43.

Jørgensen, A. M. M. y G. Arli (2012): "Los vocativos en el lenguaje juvenil de Santiago de Chile y de Madrid”. En García, C. y M. E. Placencia (Eds.), Estudios de variación pragmática en español, Buenos Aires: Dunken, pp. 141-166.

Koch, P. y W. Oesterreicher, (2007 [1990]): Lengua hablada en la Romania: español, francés, italiano, Madrid: Gredos.

Ladjali, C. (2007): Mauvaise langue, Paris: Seuil.

Lázaro Carreter, F. (1979): “Una jerga juvenil: el 'cheli' “, ABC, 14/10/1979.

Lázaro Carreter, F. 1980 [1978]: “Lenguaje y generaciones”. En Estudios de lingüística, Barcelona: Crítica, cap. 11.

Lázaro Carreter, F. (1999): “Supertriste”, Tribuna: El dardo en la palabra, El País, 04/04/1999. https:/elpais.com/diario/1999/04/04/opinion/923176803_850215.html 
Llopis, A. y Pons Bordería, S. (2020): “La gramaticalización de 'macho' y 'tío/a' como ciclo semántico-pragmático", Círculo de Lingüística Aplicada a la Comunicación, 82, pp. 151-164. https://revistas.ucm.es/index.php/CLAC/article/view/71824

Mamajón. J. (2014): Estilos comunicativos y diferencias de género en el habla infantil. Trabajo Final de Grado dirigido por A. Blanco, Guadalajara: Universidad de Alcalá.

Mancera, A. (2009): Oralización de la prensa española: la columna periodística, Berna: Peter Lang.

Manzano Arzate, J. (2010): "Nietzsche: médico de la actualidad y una visión de Píndaro" La Colmena, 65-66, 2010, pp. 37-46

Marrades, J. (2014): “Sobre la noción de 'forma de vida' en Wittgenstein”, Ágora, Papeles de Filosofia , 33/1, pp. 139-152

Martinell, E.; Forment, M y N. Vallés (2002): “Aproximación al lenguaje gestual de los adolescentes”. En Rodríguez González, F. (ed.), El lenguaje de los jóvenes, Ariel, pp. 165191.

Martinet, A. (1960): Éléments de linguistique générale, París: Armand Colin.

McLuhan, M. (1964): Understanding Media: The Extensions of Man,

Mendoza Berjano, R, (2008): La adolescencia como fenómeno cultural. Lección inaugural curso académico 2008/2009, Huelva: Servicio de Publicaciones de la Universidad de Huelva.

Ministerio de Educación y Formación Profesional (s. d.): Competencia en Comunicación Lingüistica. http://www.educacionyfp.gob.es/educacion/mc/lomce/curriculo/compet encias-clave/liguistica.html

Molina, I. (2010): "Difusión social de una innovación lingüística: la intensificación en las jóvenes madrileñas", Oralia, 13, pp. 197-214.

Morán, C. (2019): "Prohibida la entrada a mayores: infancia y adolescencia en la narrativa española actual". En Celma, M. P. y C. Morán, La verdadera patria infancia y adolescencia en el relato español contemporáneo, Madrid-Frankfurt a. M.: Iberoamericana/ Vervuert, pp. $7-24$.

Moreno Fernández, F. (1998): Principios de sociolinguística y sociología del lenguaje, Barcelona: Ariel.

Moreno Fernández, F. (2020): La lengua y el sueño de la identidad, Canterano: Aracne editrice. 
Nawas, M. M. (1971): "El estilo de vida", Revista Latinoamericana de Psicología, 3 (1), pp. 91-107 https://www.redalyc.org/pdf/805/80503105.pdf

Norton, R. W. y L. S. Pettegrew (1977): "Communicator Style as an Effect Determinant of Attraction", Communication Research, 4 (3), pp. 257-282.

Olímpio de Oliveira M. E. (2015): "Aportaciones de la Etología Humana a los estudios lingüísticos: el caso de la Fraseología”, Pragmalingüística, 23, pp. 151-170.

Ortega y Gasset, J. (2004): Obras completas, Madrid: Taurus-Fundación José Ortega y Gasset.

Portolés, J. (2011/2012): “Cortesía pragmática e historia de las ideas: face y freedom”, Onomázein 24, pp. 223-244.

Raya, I., I. Sánchez-Labella y V. Durán (2018): "La construcción de los perfiles adolescentes en las series de Netflix Portrece razones y Atípico", Comunicación y medios, 27 (37), pp. 131-143.

Reyes, G. (2018): Palabras en contexto. Pragmática y otras teorías del significado, Madrid: Arco/ Libros.

Rodríguez González, F. (2006): "Medios de comunicación y contracultura juvenil”, Círculo de lingüistica aplicada a la comunicación, 25, pp. 5- 30. https://rua.ua.es/dspace/bitstrea

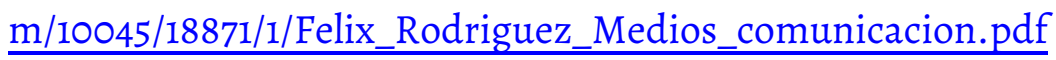

Rodríguez Merchán, E. (2013): “Adolescentes en el cine”, Revista de Estudios de Juventud, 101, pp. 19-33.

Steiner, G. y C. Ladjali (2005 [2003]): Elogio de la transmisión. Maestro y alumno (trad. esp.), Madrid: Siruela.

Stenstróm, A.-B. y A. M. Jørgensen (2011): "La pragmática contrastiva basada en el análisis de corpus: perspectivas desde el lenguaje juvenil". En Fant, L. y A. M. Harvey (2011). El diálogo oral en el mundo hispanohablante: estudios teóricos y aplicados, Madrid- Frankfurt a. M.: Editorial Iberoamericana / Vervuert, pp. 251-276.

Silva-Corvalán, C. y Enrique-Arias, A. (2017): Sociolingüística y pragmática del español, Washington, D.C.: Georgetown University Press.

Tanner, D. (2005 [1984]): Conversational Style: Analyzing Talk Among Friends. Oxfor: Oxford University Press.

Tisseron, S. (2011): "Intimité et extimité", Communications, 88, pp. 83-91. https://www.persee .fr/doc/comm_0588-8018_2011_num_88_1_2588 
Valente, J.Á. (1971): Las palabras de la tribu, Madrid: Siglo XXI de España editores.

Valenzuela, J. (1918): "Palabrotas, tacos y juramentos: la ciencia del lenguaje tabú", Ciencia Cognitiva, 12 (3), 51-53. http://www.cienciacognitiva.org/?p=1703

Wood, D. (2015): Fundamentals of Formulaic Language, Londres/ N. York: Bloomsbury Publishing Plc.

Zimmermann, K. (2005): "Lenguaje juvenil, comunicación entre jóvenes y oralidad". En Kotschi, T. et al. (Coords.), El español hablado y la cultura oral en España e Hispanoamérica, Madrid-Frankfurt a. M.: Iberoamericana/ Vervuert, pp. 475-514. 